\title{
EDUCADORA OU TIA: OS REFLEXOS DA FEMINIZAÇÃO DO MAGISTÉRIO NA CONSTRUÇÃO DA IDENTIDADE PROFISSIONAL DE PROFESSORES (AS) DA EDUCAÇÃO INFANTIL
}

\author{
ANDRÉA RODRIGUES DE SOUZA \\ JOSÉ CARLOS DE MELO \\ Universidade Federal do Maranhão (UFMA), São Luís, Maranhão, Brasil
}

\begin{abstract}
Resumo: O presente artigo configura-se como um recorte de uma pesquisa de pósgraduação em docência na educação infantil, tendo como objetivo principal analisar os reflexos do processo de feminização da docência na construção da identidade profissional das professoras de educação infantil em uma rede pública municipal, a partir dos conhecimentos adquiridos no curso de especialização em docência na educação infantil (CEDEI). A pesquisa se caracteriza como exploratória e possui uma abordagem qualitativa. Os instrumentos de coleta de dados utilizados foram um questionário semiestruturado e a observação não participante. Concluiu-se que na atualidade o mito da educadora nata ainda é muito presente, mas aos poucos vem sendo desconstruído, dando ênfase à profissionalização docente e à construção/fortalecimento de sua identidade.
\end{abstract}

Palavras-chave: Feminização. Gênero. Educação Infantil. Identidade.

\section{INTRODUÇÃO}

Atualmente muito se tem discutido acerca da profissionalização dos professores que atuam nas instituições de educação infantil. De acordo com a Lei 9.394/96, a educação infantil é considerada a primeira etapa da educação básica e tem como objetivo promover o desenvolvimento integral da criança, mas nem sempre foi assim. Durante muitos anos o tipo de educação voltada para essa faixa etária possuía um caráter extremamente assistencialista e compensatório, e a formação ofertada para atuar nesta etapa de ensino era praticamente inexistente.

Não havia, até a promulgação da atual LDB, uma especificação legal quanto à formação do educador de crianças pequenas, o que vigorava era a ideia da mulher como educadora nata, que possuía um "dom"1 natural para cuidar e educar crianças. Destaca-se que esse estereótipo é uma construção social acerca do gênero feminino que se perpetuou ao longo da história, sobretudo após a inserção da mulher no magistério, no final do século XIX e início do século XX (ARCE, 2002).

Esse artigo configura-se como um recorte de uma pesquisa de pós-graduação em docência na educação infantil, ofertada às professoras que atuam nesta etapa em uma 
rede pública municipal. O objetivo principal foi analisar os reflexos do processo de feminização da docência na construção da identidade profissional dessas educadoras, a partir dos conhecimentos adquiridos no Curso de Especialização em Docência na Educação Infantil (CEDEI), ofertado pelo Ministério da educação (MEC), em parceria com as universidades federais brasileiras.

A pesquisa se caracterizou como exploratória, que, de acordo com Gil (1999), possui como objetivo desenvolver, esclarecer e modificar ideias e conceitos. Optou-se pela abordagem qualitativa, segundo Bodgan e Biklen (2003), na qual os dados são obtidos através do contato direto do pesquisador com a realidade a ser estudada, em que se enfatiza mais o processo do que o produto. Utilizou-se como instrumentos de coleta de dados um questionário semiestruturado e a observação não participante, que, segundo Marconi e Lakatos (1996), é aquela em que o pesquisador entra em contato com a realidade estudada, presenciando o fato mas não participando dele.

Este artigo está assim estruturado: na primeira parte tem-se a introdução, na qual esclarece o seu objeto de estudo; na segunda parte, apresenta-se uma breve exposição do processo de feminização do magistério e do conceito de identidade; na terceira parte, a pesquisa empírica, e por fim apresentam-se as considerações finais, nas quais os autores se posicionam sobre a temática em questão.

\section{O PROCESSO DE FEMINIZAÇÃO DO MAGISTÉRIO NO CONTEXTO BRASILEIRO}

De acordo com Louro (2011), o processo de inclusão da mulher na educação se deu de forma dupla (alunas/professoras), uma vez que a presença feminina no cenário educacional brasileiro ocorreu muito tempo após a sua implementação no país, considerando a sociedade patriarcal da época e as mudanças políticas e sociais que estavam ocorrendo. Assim sendo, destaca-se que a inserção feminina nas escolas de primeiras letras e posteriormente nas escolas normais ocorreu num período em que o país passava por uma série de mudanças nos aspectos políticos, sociais e econômicos ${ }^{2}$.

É válido afirmar que o papel social feminino estabelecido desde o período da colonização era simplesmente o de esposa e mãe, estereótipo construído sobre a égide do pensamento religioso, sendo a maternidade a principal função conferida à mulher. Além disso, sobre ela recaía a responsabilidade de educar as crianças nos primeiros anos de vida. Nota-se que a mulher, nessa época, encontrava-se presa ao ideário religioso, que fazia com que ela moldasse seu comportamento "adequando-os às exigências morais, alienando-se da vida pública e ligando-se cada vez mais ao cotidiano que envolvia os afazeres domésticos e os cuidados com os filhos na primeira infância" (ARCE, 2002, p. 81).

Observa-se do exposto que, quando os portugueses chegaram ao país, trouxeram uma concepção de mulher conforme o ideário europeu da época, ou seja, da Idade Média, em que a mulher era vista como um ser inferior, devendo obedecer ao homem. Destaca-se que, em nível de educação, as mulheres pertencentes à classe burguesa eram educadas em seus lares e aprendiam sobre religião, música a afazeres femininos, ou seja, não tinham direito a uma educação formal, situação essa que diferia das mulheres das classes menos favorecidas, que não recebiam nenhuma instrução e permaneciam analfabetas e excluídas da vida social (SANTANA, 2012). 
Com a criação das escolas de primeiras letras no ano de 1827, o governo determinou que o ensino desenvolvido nessas escolas deveria ser realizado por meio do método mútuo, também conhecido como método lancasteriano, desenvolvido pelo inglês Joseph Lancaster (1788-1838), em que o professor selecionava alguns alunos que desempenhavam a função de monitores, ficando responsáveis em orientar um grupo de dez alunos. Esta lei também estabelecia que os professores na época fossem "treinados" nesse método, especialmente os que atuavam nas capitais das províncias (SAVIANI, 2009).

Diante do exposto, percebe-se que havia uma "preocupação" por parte das autoridades em relação à formação do professor. Contudo, foi somente no final do século XIX e início do século XX, que houve uma ação mais concreta em relação à formação de professores, com o surgimento das denominadas escolas normais. A primeira escola normal do país foi inaugurada no ano de 1835 , na província do Rio de Janeiro. A priori, essa instituição era destinada a formar professores para suprir a demanda do ensino primário público que estava em expansão (LOURO, 1997).

De acordo com Tanuri (2000), além do método mútuo, o currículo da escola normal possuía na sua grade disciplinas como matemática (as quatro operações e proporções), língua portuguesa, geografia e os princípios da moral cristã. Além disso, para ser admitido na escola normal o candidato deveria ser cidadão brasileiro, ter 18 anos, saber ler e escrever e ter um bom comportamento moral.

Nos anos posteriores, a escola normal passou por algumas transformações, dentre elas a admissão da matricula de mulheres, contribuindo para sua inserção no magistério, uma vez que o ensino primário no país encontrava-se em expansão e os homens buscavam oportunidades em outras áreas profissionais. Ressalta-se que, com o declínio dos homens no exercício da docência, as mulheres se tornaram maioria no magistério, ocorrendo a feminização da docência, como destaca Louro (1997).

Assim sendo, observa-se que o processo de inserção da mulher no magistério se deu a partir de uma necessidade política/econômica, pois havia diferença salarial entre o sexo masculino e feminino. Também não se pode negar a influência da religião, pois o magistério passou a ser visto como uma profissão por excelência feminina, sustentada pela ideia de que a mulher era "naturalmente" preparada para cuidar das crianças pequenas.

De acordo com Louro (1997), a atividade docente passou a ser associada com características naturalmente "femininas" como, por exemplo, a afetividade, paciência, doação e o "jeito" para lidar com crianças. O magistério constituía-se como sacerdócio e não como profissão, deixando a mulher na posição de "mãe espiritual", onde cada aluno (a) deve ser visto (a) como seu próprio filho (a).

Nos anos posteriores, a escola normal manteve sua hegemonia no que diz respeito à formação de professores para atuar no ensino primário. De acordo com Saffioti (1976), foi somente no ano de 1953 que o ingresso da população feminina no curso de pedagogia foi liberado. Já na educação infantil o mito da "educadora nata" era bem mais presente, e apesar de existirem cursos de magistério em nível médio, o que se observava na prática era que, para trabalhar nas instituições de educação infantil, o único requisito exigido era saber ler e escrever.

Sobre o mito da mulher como educadora nata, Arce (2002) constatou em suas pesquisas que essa concepção predomina no que diz respeito à imagem do profissional que atua na educação infantil. A autora destaca ainda que essa imagem foi reforçada ao 
longo dos anos por meio dos clássicos da educação infantil, e também dos "documentos oficiais editados pela Fundação Movimento Brasileiro de Alfabetização (MOBRAL) e pelo Ministério da Educação e cultura (MEC), final da década de 70 até o ano de 1995" (ARCE, 2002, p. 168).

Foi somente em 1996, com a promulgação da Lei de diretrizes e bases e dos demais documentos oficiais ${ }^{3}$ que norteiam a educação infantil, que a formação exigida para atuar nessa etapa de ensino e nos anos iniciais passou a ser o nível superior, admitindo-se como formação mínima o curso normal em nível médio (BRASIL, 1996).

Como é sabido, a educação brasileira, bem como o processo de formação profissional docente, sofreu diversas transformações ao longo dos últimos anos. Os conceitos de criança e infância também foram modificados e a criança passou a ser compreendida como um sujeito de direitos, dentre eles, o de ter acesso a uma educação não assistencialista e nem compensatória, o que refletiu diretamente na mudança no perfil profissional do educador de crianças pequenas, conforme destaca Machado (2000):

Se há tempos atrás o profissional leigo, paciente e afetivo satisfazia a expectativa social para a função de cuidar das crianças pequenas enquanto suas mães estavam trabalhando, a exigência de um docente especialmente qualificado e com nível de escolaridade mais elevado vem responder ao clamor de democratização da educação e de melhoria da qualidade do atendimento (MACHADO, 2000, p. 195).

Segundo a autora, o novo perfil profissional exigido na atualidade para atuar na educação infantil trouxe consigo muitos desafios, dentre eles destaca-se a necessidade de se ter uma formação inicial/continuada que propicie o desenvolvimento de um trabalho adequado às necessidades das crianças pequenas e também a necessidade de formar as professoras que já lecionavam nas escolas, influenciando diretamente na construção de sua identidade docente, como será no próximo tópico.

\section{IDENTIDADE, IDENTIDADE PROFISSIONAL E SEUS CONCEITOS}

A constituição da identidade de um professor (a) é algo bastante complexo, podendo ser compreendida como singular e ao mesmo tempo distinta, ou seja, é constituída pela identidade pessoal e profissional, sendo definida pelo equilíbrio entre as características pessoais e profissionais. Segundo Dubar (2005), essa identidade é constituída nas relações sociais estabelecidas com a instituição educativa e os demais sujeitos que dela participam cotidianamente influenciando nessa construção, ou seja, constituem-se por meio de um jogo dialético entre o profissional e a sociedade na qual ele/a está inserido.

Existem no campo da psicologia, antropologia e sociologia diversos estudos acerca da categoria "identidade", dentre eles destaca-se o estudo de Ciampa (2007), baseado na psicologia social. $O$ autor enfatiza que a identidade pode ser comparada com um processo de metamorfose, ou seja, que ela é algo que está em constante transformação e se constrói por meio das relações sociais, constituindo-se no produto transitório entre a interação do indivíduo e sua história com o meio social no qual está inserido. 
No campo da sociologia, Dubar (2005) e Bauman (2005) apresentam o conceito sociológico do termo. O primeiro autor tem se dedicado ao estudo da identidade profissional, destacando que o local de atuação do sujeito influencia fortemente na construção da sua identidade. O autor utiliza a expressão "formas identitárias", por entender que o ser humano assume diversas identidades diante dos mais variados contextos e papéis sociais a ele conferidos.

Já o sociólogo Bauman (2005) conceitua a identidade como autodeterminação, ou seja, a postulação do "eu". Em seus estudos, o autor afirma que o conceito de identidade não se configura como um exercício fácil ao entender que:

A identidade sejamos mais claros sobre isso, é um "conceito altamente contestado." Sempre que ouvir essa palavra, pode-se estar certo de que está havendo uma batalha. O campo de batalha é o lar natural da identidade (BAUMAN, 2005, p.83).

Observa-se do exposto que a identidade não é algo pronto e acabado, mas é construído ao longo da vida, por meio das experiências que o indivíduo vivencia ao longo da sua trajetória. $\mathrm{O}$ autor destaca ainda que, na modernidade, o ser humano possui "várias identidades" à sua escolha, podendo inventar muitas outras e que alguns elementos constitutivos de nossa identidade estão diretamente relacionados com os "outros", relação essa nem sempre amigável, mas que ocorre de forma lenta e permanente.

No que diz respeito à identidade profissional do professor de educação infantil, é válido afirmar que o processo de feminização da docência esteve aliado ao mito da educadora nata durante muitos anos, conferindo a essa categoria (majoritariamente composta por mulheres) uma imagem não profissional. Aliada a um passado não tão recente, cuja oferta da educação infantil em instituições públicas era baseada no princípio do assistencialismo, compreende-se que não havia um "perfil" definido para este profissional, além dos estereótipos socialmente construídos sobre a "tia ou a professorinha do jardim de infância", que é aquela pessoa apta naturalmente para cuidar das crianças pequenas, não necessitando de formação especifica, reduzindo seu trabalho a uma função maternal (ARCE, 2002).

Nesse sentido, buscou-se compreender como o processo de feminização da docência, assim como os resquícios de uma educação infantil assistencialista e compensatória, tem influenciado a construção/fortalecimento da identidade profissional das professoras de uma rede pública municipal, a partir dos conhecimentos obtidos junto ao curso de especialização em docência na educação infantil (CEDEI), como será demonstrado a seguir.

\section{IDENTIDADE PROFISSIONAL E FORMAÇÃO DOCENTE: COM A PALAVRA, AS DOCENTES}

O processo de formação inicial/continuada é um instrumento importante na construção de uma identidade profissional. Além disso, pode-se destacar que essa formação, aliada a uma prática contínua, possibilita ao (à) educador (a) encontrar alguns elementos que o (a) ajudarão a se enxergar enquanto um (a) profissional da educação.

Esta pesquisa foi realizada com trinta alunas do CEDEl que são docentes ${ }^{4}$ e outras que ocupam o cargo de gestoras de uma rede pública municipal. Teve por objetivo analisar os reflexos do processo de feminização do magistério na construção da 
identidade dessas profissionais, que se encontravam em processo de formação continuada.

Ao serem questionadas sobre a existência de um perfil para as profissionais de educação infantile como seria esse perfil, as docentes destacaram que:

O educador tem que ser carismático, paciente, ter afeto e transmitir amor e compreensão, além de saber lidar com a criança (D 11).

Sim, paciente, inovador, investigador, compreensivo, criativo, parceiro e acima de tudo gostar do que está fazendo (D 26).

Nota-se nos depoimentos acima que a concepção sobre o perfil das educadoras de crianças pequenas se remete ao conceito de gênero ${ }^{5}$, em que a imagem da mulher enquanto educadora nata é o modelo a ser seguido. Observa-se que D11 destaca na sua fala elementos como paciência, afeto, compreensão e saber "lidar" com a criança. Já D23, "além dos elementos já citados, enfatiza que o professor tem que gostar do que faz".

Esse sentimento de identificação "natural" com a profissão foi constatado por Arce (2002) quando afirma que a construção da imagem da mulher enquanto professora na educação brasileira tem sido apresenta e reforçada como:

A imagem ideal da profissional para a educação infantil como da mulher "naturalmente" educadora nata, passiva, paciente, amorosa, que sabe agir com bom senso, é guiada pelo coração em detrimento da formação profissional. A não valorização salarial, a inferioridade perante os demais docentes, a vinculação do seu trabalho como doméstico, o privado, e a deficiência na formação aparecem como resultado desta imagem, que traz na sua base as determinações de gênero e a divulgação de uma figura mitificada deste profissional, que não consegue se desvincular dos mitos que interligam a mãe e a criança (ARCE, 2002, p. 02).

A autora aponta que as dificuldades enfrentadas na prática são resultantes, dentre outras coisas, da falta de formação específica para esse educador (a), tendo em vista que a semelhança existente entre o trabalho desenvolvido com as crianças, sobretudo nas creches, pelas profissionais com a função materna, traz na sua gênese as determinações de gênero e, consequentemente, a criação e divulgação dessa imagem feminina.

Ainda sobre o perfil docente para atuar na educação infantil, foram apresentadas as seguintes respostas:

Acredito que sim, este profissional precisa além de se identificar com a área ter conhecimento das especificidades da criança (D9).

Sim. Em primeiro lugar o profissional de educação infantil deve ter como foco principal do seu trabalho a criança, deve respeitar e valorizar a realidade e os conhecimentos adquiridos pela criança, além de entender que esta é um sujeito sócio histórico, com direitos e necessidades (D1).

Mulheres, muitas vezes cansadas, mas dedicadas ao trabalho (D12). 
Observa-se no depoimento de D9 e D1, que as participantes da pesquisa enfatizam algumas categorias como o profissionalismo, o conhecimento sobre a criança e a infância, assim como da educação infantil, destacando um novo "perfil" profissional para o educador de crianças pequenas, que se baseia em uma formação mais sólida tanto de cunho inicial como continuada, deixando de lado os estereótipos socialmente construídos, sobretudo acerca do papel feminino desempenhado pela tão rotulada "tia". Sobre a importância da formação docente para atuar na educação infantil, Kramer (2005) assegura que:

A formação é necessária não apenas para aprimorar a ação do profissional ou melhorar a prática pedagógica. A formação é direito de todos os professores, é conquista e direito da população, por uma escola pública de qualidade. Podem os processos de formação desencadear mudanças? Sim, se as práticas concretas feitas nas creches, pré-escolas e escolas e aquilo que sobre elas falam seus profissionais forem o ponto de partida para as mudanças que se pretende implementar (KRAMER, 2005 , p. 224).

Dessa forma, compreende-se que a formação pedagógica é uma forte aliada para a superação das práticas assistencialistas no contexto educacional brasileiro, especialmente quando se coloca os professores como sujeitos autônomos e que protagonizam o seu desenvolvimento profissional, tendo como objeto de seu trabalho a criança, que deve desenvolver na educação infantil suas capacidades físicas, emocionais e cognitivas.

Destaca-se o depoimento de D12 quando esta afirma que o perfil do professor que atua na área é composto de mulheres "cansadas, mas dedicadas ao trabalho". Sabese com clareza que a profissão docente é extremamente desgastante e mal remunerada, e que a carga de trabalho dos professores varia de acordo com o nível escolar em que o docente atua.

Outra característica relevante sobre o tema são as condições de trabalho desses profissionais; que tipo de dificuldade eles enfrentam? Quais são seus maiores desafios? Nota-se aspectos como o tempo de trabalho dedicado aos alunos, a quantidade de alunos e a "carga" emocional demandada pelas relações com seus alunos e com outros profissionais são fatores que contribuem para o desgaste físico e mental das professoras, fora suas demais atribuições como a preparação das aulas, as atividades extras, avaliações, etc. Tudo isso aliado à dupla jornada de trabalho dessas mulheres, somada à constante necessidade de aperfeiçoamento pelo qual necessitam passar, embora sempre encontraram diversas razões para exercer sua profissão (TARDIF, LESSARD, 2009).

Quando questionadas sobre como as diversas nomenclaturas (tia, cuidadora, jardineira, etc.) utilizadas para "nomear" a profissional de educação infantil ao longo do tempo tem influenciado na construção e consolidação da identidade docente destas profissionais, as docentes destacam que:

Sim, de forma negativa e reducionista, influenciando na forma como a sociedade vê as professoras de educação infantil (D30).

Muito, até hoje existem professoras que não se reconhecem como profissionais da educação (D14). 
Influenciam de maneira errada, pois acabam nos vendo como alguém que cuida como a mãe e não como alguém que transmite conhecimento e forma cidadãos críticos e formadores de opiniões (D20).

Devemos mudar essa situação, ao longo do tempo ficamos conhecidas como tias, mas somos professoras e precisamos ser vistas como profissionais (D23).

Com base nos depoimentos das docentes sobre a influência dos termos tia, cuidadora, dentre outros, que ainda são muito utilizados para designar a professora de educação infantil, percebe-se que essas nomenclaturas deixaram um aspecto negativo em relação ao processo de construção identitária das professoras de educação infantil, como destacou D14 em sua fala ao afirmar que algumas educadoras ainda não conseguiram se desvincular do estereótipo de educadora nata, não compreendendo que a sua profissão exige tanto saberes específicos como qualquer outra.

Sobre a utilização do termo "tia", Novaes (1992) aponta que este termo foi estabelecido na educação pré-escolar a partir da década de 1960, e na educação primária durante a década de 1970. Segundo a autora, um dos motivos pelos quais essa terminologia foi empregada foi a sensação de segurança "emocional" que as mães sentiam pela culpa de trabalharem fora do lar, pois ao entregarem seus filhos à tia, sentiam-se aliviadas por deixarem os mesmos com uma figura amiga, boa, e que gostava de crianças.

Tal fato, associado ao mito da "educadora nata", bem como o processo de feminização do magistério, criou no imaginário social uma imagem distorcida em relação à profissão docente. De acordo com Almeida (1998), isso se deu em virtude de que, por muitos anos, a profissão de professora foi:

Praticamente a única em que as mulheres puderam ter o direito de exercer um trabalho digno e conseguir uma inserção no espaço público, dado que os demais campos profissionais lhes foram vedados. $O$ fato de não ingressarem nas demais profissões, acessíveis somente ao segmento masculino, e a aceitação do magistério, aureolados pelos atributos de missão, vocação e continuidade daquilo que era realizado no lar, fizeram que a profissão rapidamente se feminizasse (ALMEIDA, 1998, p. 23).

Assim sendo, é válido afirmar que, devido a essas questões, a profissão docente, sobretudo na educação infantil e nos anos iniciais, cujo público docente é constituído majoritariamente por mulheres, passou a ser desvalorizada, uma vez que tanto o termo "tia" quantos outros associados a essas etapas de educação, trazem em seu bojo a falsa concepção de que qualquer mulher pode ser uma professora. Com relação aos papéis de tia ou professora, Freire $(1997$, p.11) afirma que "ensinar é profissão que envolve certa tarefa, certa militância, certa especificidade no seu cumprimento, enquanto ser tia é viver uma relação de parentesco", ou seja, não se pode reduzir a figura da professora à condição de um parente próximo.

Ainda sobre este tema, as docentes que participaram do CEDEl enfatizam que:

Tem bastante influencia na questão do carinho/afeto (D17). 
SOUZA, A. R.; MELO, J. C.

Vejo como uma forma de carinho, o fato de a professora ser chamada de tia não faz dela menos profissional (D2).

Acredita-se que essas expressões são utilizadas como forma de carinho e ao mesmo tempo para aproximar a criança do profissional (D25).

Acredito que tais nomenclaturas estão diretamente relacionadas com a afetividade, quando não se compreende a importância da afetividade, pode-se compreender como sendo pejorativas tais nomenclaturas (D28).

Novamente os depoimentos fazem menção ao conceito de mulher enquanto educadora natural e remetem à ideia da professora enquanto um membro da família. Observa-se ainda que as docentes unanimemente compreendem essas nomenclaturas como formas de demonstrar afeto e carinho, a exemplo de D28 ao enfatizar que, quando não se compreende a importância da afetividade na relação aluno/professor, essas nomenclaturas podem ser entendidas como pejorativas.

Sabe-se que a afetividade é um fator de suma importância nas relações estabelecidas entre a criança e os "outros", desempenhando um papel muito importante no desenvolvimento dos pequenos. Sobre o conceito de afetividade, concorda-se com Wallon (1984) ao afirmar que esse é:

Um domínio funcional cujo desenvolvimento depende da ação de dois fatores: orgânico e o social. Entre estes dois fatores existem uma relação recíproca que impede qualquer tipo de determinação no desenvolvimento humano, tanto que a constituição biológica da criança ao nascer não será a lei única de seu futuro destino. Os seus efeitos podem ser amplamente transformados pelas circunstâncias da sua existência onde a escolha individual não está ausente (WALLON, 1984, p.288).

Diante do exposto, compreende-se que a afetividade é importante para o desenvolvimento da criança, mas ao mesmo tempo ressalta-se que, no ambiente escolar, a afetividade deve ser diferenciada de suas manifestações, distinguindo-se do sentimento da paixão e da emoção, uma vez que, segundo Wallon (1984), esse termo é utilizado para identificar um domínio funcional abrangente, envolvendo a ação dos fatores de cunho orgânico e social.

Nesse sentido, pode-se afirmar que na educação infantil, como em qualquer outra etapa de escolarização, a aprendizagem está profundamente ligada à vida afetiva, por isso torna-se necessário que a escola, assim como seus professores, amplie e fortaleça esse laço, criando um ambiente sócio afetivo saudável para as crianças da etapa de escolarização básica. Entretanto, ressalta-se que a afetividade não deve ser encarada pelo (a) educador (a) de crianças pequenas apenas como manifestação de carinho, pois é necessário que o professor compreenda, à luz da teoria, como essa categoria vai influenciar no desenvolvimento cognitivo de seus alunos (WALLON, 1984).

Esta é, sem dúvida, uma discussão que suscita inúmeros embates teóricos, haja vista que o processo de feminização docente a priorifoi o responsável pela inculcação da ideologia de que a mulher possui aptidões inatas para o trabalho, desvalorizando seu trabalho e desconsiderando as especificidades da criança como, por exemplo, o direito de ter uma educação que promova o seu desenvolvimento integral.

Assim sendo, Lima (2013) afirma que o profissional deve estar apto a assumir, no seu trabalho, tanto o aspecto do educar quanto do cuidar, em virtude de ambos serem indissociáveis, tendo sempre o cuidado de se preparar para exercer as duas funções ao 
mesmo tempo, não tendendo a pender mais para o lado pedagógico ou para o afetivo, desconsiderando a importância do equilíbrio entre ambas as funções.

\section{CONSIDERAÇÕES FINAIS}

Ao longo dessa investigação observou-se que a construção da identidade profissional das professoras de educação infantil no Brasil se constituiu sob a égide do processo de feminização do magistério, que criou o estereótipo da figura feminina como sendo naturalmente dotada de atributos que Ihe conferiam a função de educadora por excelência.

Em contrapartida, com o passar dos anos, o conceito de criança e infância foi se modificando, e consequentemente o papel da educação e do educador, trazendo à baila diversos debates teóricos sobre a necessidade da profissionalização docente, especialmente para os professores que atuam na educação infantil e nos anos iniciais do ensino fundamental, bem como a criação de leis que contemplassem o direito das crianças brasileiras a ter uma educação pública de qualidade, e dos professores a uma formação inicial/continuada, a fim de promover mudanças gradativas no contexto educacional no país.

A pesquisa constatou que a maioria das educadoras da rede municipal estudada compreende que o processo de construção da identidade profissional do educador (a) de crianças pequenas possui as marcas de um passado de práticas assistencialistas na educação infantil, passado esse não tão recente e que ainda hoje faz parte do imaginário social, traduzindo-se, por exemplo, na figura da tão conhecida "tia", conferindo à educadora um status de membro da família (que não se casou e nem teve filhos, estando "fadada" a cuidar dos sobrinhos, dando-lhes carinho e afeto), e não o de uma profissional qualificada para o exercício da docência junto a essa faixa etária.

Algumas falas também se reportaram à ideia de que, por se tratar de uma figura feminina, a mulher seria considerada mais apta para o trabalho com as crianças pequenas, tal fato é ilustrado na história europeia e brasileira, tendo a profissional de educação infantil sido denominada de "jardineira, mestra, tia e professorinha", ao longo desses anos. Essa ambiguidade entre o doméstico e o cientifico chegou até os dias atuais configurando uma caracterização pouco definida dessa profissional, revezando-se entre os papeis de mulher/mãe e o trabalho de educar (ARCE, 2001).

Concluiu-se que na atualidade o mito da educadora nata ainda é muito presente, mas aos poucos vem sendo desconstruído, dando ênfase à profissionalização docente e, consequentemente, à criação de um novo "perfil" de educadores (as) que atuam nesta etapa de ensino, contribuindo para a construção/fortalecimento da sua identidade profissional.

Esta pesquisa pode contribuir de forma significativa para o enriquecimento pedagógico tanto na área de formação inicial/continuada de professores na educação infantil quanto na construção e no fortalecimento da identidade docente das profissionais que atuam nas instituições de educação infantil na rede municipal estudada, compreendendo que o processo formativo e da constituição identitária de cada professor (a) acontece de forma contínua e permanente. 


\title{
EDUCATOR OR TIA: THE REFLEXES OF THE FEMINIZATION OF TEACHING IN CONSTRUCTION OF THE PROFESSIONAL IDENTITY OF CHILD EDUCATION TEACHERS
}

\begin{abstract}
This article is part of a postgraduate research in teaching in child education, whose main objective is to analyze the reflexes of the teaching feminization process in construction of the professional identity of child education teachers in a municipal public education, based on the knowledge acquired in the specialization course in teaching in child education (CEDEI). The research is characterized as exploratory and has a qualitative approach. The instruments used for data collection were a semi-structured questionnaire and non-participant observation. It was concluded that, currently, the myth of the born teacher is still very present, but gradually has been deconstructed, emphasizing teacher professionalization and the construction / strengthening of teachers identity.
\end{abstract}

KEYWORDS: Feminization. Genre. Child education. Identity.

\section{EDUCADORA O TIA: LOS REFLEJOS DE LA FEMINIZACIÓN DEL MAGISTERIO EM LA CONSTRUCCIÓN DE LA IDENTIDAD PROFESIONAL DE PROFESORES (AS) DE LA EDUCACIÓN INFANTIL}

RESUMEN: El presente artículo se configura como un recorte de una investigación de postgrado en docencia en la educación infantil, teniendo como objetivo principal analizar los reflejos del proceso de feminización de la docencia en la construcción de la identidad profesional de las profesoras de educación infantil en una red publica municipal, a partir de los conocimientos adquiridos en el curso de especialización en docencia en la educación infantil (CEDEI). La investigación se caracteriza como exploratoria y tiene un enfoque cualitativo. Los instrumentos de recolección de datos utilizados fueron un cuestionario semiestructurado y la observación no participante. Se concluyó que en la actualidad el mito de la educadora nata todavía es muy presente, pero poco a poco viene siendo desconstruido, dando énfasis a la profesionalización docente y la construcción / fortalecimiento de su identidad.

PALABRAS CLAVE: Feminización. Género. Educación Infantil. Identidad.

\section{NOTAS}

1) Dom: um presente, uma dádiva dada a alguém gratuitamente.

2) Trata-se do período de transição que compreende o fim da monarquia e a implantação da primeira república.

3) Constituição Federal (1988), Estatuto da criança e do adolescente-ECA (1990), Lei de Diretrizes e Bases-LDB (1996), Referencial curricular nacional para a educação infantil-RCNEI (1998), Diretrizes 
curriculares nacionais para a educação infantil-DCNEI (1999) e mais recentemente a Base nacional comum curricular-BNCC (2016).

4) Para resguardar a identidade das participantes, estas serão denominadas de D1 a D30.

5) De acordo com Scott (1990) Gênero é um elemento constitutivo das relações sociais fundadas sobre as diferenças percebidas entre os sexos.

\section{REFERÊNCIAS}

ALMEIDA, J. S. Mulher e educação: a paixão pelo possível. São Paulo: Unesp, 1998.

ARCE, A. Documentação Oficial e o mito da educadora nata na educação infantil. Cadernos de Pesquisa, São Paulo, n.113, 167-184, junho 2001.

- A Pedagogia na "era das revoluções": uma análise do pensamento de Pestalozzi e Froebel. Campinas: Autores Associados, 2002.

BAUMAN, Z. Identidade. Trad. Carlos Alberto Medeiros. Rio de Janeiro: Jorge Zahar, 2005.

BOGDAN, R. S.; BIKLEN, S. Investigação qualitativa em educação: uma introdução à teoria e aos métodos. 12. ed. Porto: Porto, 2003.

BRASIL, Lei de Diretrizes e Bases da Educação Nacional. 1996.

CIAMPA, A. C. A estória do Severino e a história de Severina. São Paulo: Brasiliense, 2007.

DUBAR, C. $A$ socialização: construção das identidades sociais e profissionais. SP: Martins Fontes, 2005.

FREIRE, P. Professora sim, tia não: cartas a quem ousa ensinar. São Paulo: Olho D'água, 1997.

GIL, A. C. Métodos e técnicas de pesquisa social. 5. ed. São Paulo: Atlas, 1999.

KRAMER, S. Profissionais de Educação Infantil: Gestão e Formação. São Paulo: Ática, 2005.

LIMA, M. S. L.; GOMES, M. O. Redimensionando o papel dos profissionais da educação: algumas considerações. In: PIMENTA, S. G.; GHEDIN, E. Professor reflexivo no Brasil: gênese e crítica de um conceito. São Paulo: Cortez, 2002.

LOURO, G. L. Gênero e Magistério: identidade, história, representação. In: CATANI, D. B. et al. (org.). Docência, memória e gênero: estudos sobre formação. São Paulo: Escrituras Editora, 1997. 
SOUZA, A. R.; MELO, J. C.

RJ: Vozes, 2011.

. Gênero, sexualidade e educação: uma perspectiva pós-estruturalista. 12 ed., Petrópolis,

MACHADO, M. L. Desafios iminentes para projetos de formação de profissionais para educação infantil. Cadernos de Pesquisa, São Paulo, n.110, jul. 2000.

MARCONI, M. A; LAKATOS, E. M. Técnicas de pesquisa: planejamento e execução de pesquisas, amostragens e técnicas de pesquisas, elaboração e interpretação de dados. 3. ed. São Paulo: Atlas, 1996.

NOVAES, Maria Eliana. Professora Primária: Mestre ou Tia. 5. ed. São Paulo: Cortez, 1992.

SAFFIOTI, H. A Mulher na Sociedade de Classes: Mito e Realidade. Petrópolis: Ed. Vozes, 1976.

SANTANA, D. R. A função da mulher na educação infantil: mãe ou professora? IX Seminário nacional de pesquisas "Histórias, sociedade e educação no Brasil", 2012. Disponível em: <www.histedbr.fe.unicamp.br>. Acessado em: 23 jul. 2017.

SAVIANI, D. Formação de professores: aspectos históricos e teóricos do problema no contexto brasileiro. Revista Brasileira de Educação, v. 14, n. 40, p. 143-155, 2009.

SCOTT, J. Gênero: uma Categoria Útil da Análise Histórica. Educação e Realidade. Ano 16, nº 2. Porto Alegre, jul./dez., 1990. p. 1-22.

TANURI, L. M. História da formação de professores. Revista Brasileira de Educação, n. 14, maio-agosto 2000, p. 61-88.

TARDIF, M; LESSARD, C. O trabalho docente: elementos para uma teoria da docência como profissão de interações humanas. Tradução de João Batista Kreuch. 5 ed., Petrópolis, RJ: Vozes, 2009.

WALLON. H. A evolução psicológica da criança. Lisboa: Edição 70, 1984.

AndRÉA Rodrigues de SOUZA: Pedagoga e especialista em Docência na educação infantil pela Universidade Federal do Maranhão (UFMA). Membro do grupo de estudos e pesquisa em educação, infância e docência (GEPEID).

E-mail: andrear.souza@hotmail.com

José Carlos de Melo: Doutor em Educação pela Pontificia Universidade Católica PUCSP. Professor do Departamento de Educação II da Universidade Federal do Maranhão (UFMA), Coordenador do grupo de estudos e pesquisa em educação, infância e docência (GEPEID).

E-mail:mrzeca@terra.com.br 